\title{
Marketing urbano e a dimensão da criatividade: colonização iminente do capitalismo flexível?
}

João Domingues ${ }^{1}$

\begin{abstract}
Resumo: Neste artigo procuro interpelar as formas gerais de gestão contemporânea das grandes cidades, sua relação com os meios de espacialização capitalista e sua articulação com o campo da cultura. Tendo como pressuposto as mudanças conjunturais do modo capitalista de produção em sua perspectiva desigual e combinada, o que se pretende esboçar é a noção de que estão em curso alterações significativas na forma de representar e agir sobre o urbano, e que estas evidenciam problematizações para a cultura, em especial no que toca ao trabalho e ao consumo. Desta forma, pretende-se investigar quais as aproximações entre o planejamento urbano hegemônico contemporâneo e a dimensão criativa do mercado de bens simbólicos. Para finalizar, procuro apresentar algumas questões para incorporar parte da questão urbana no investimento político que opera as dimensões da criatividade.
\end{abstract}

Palavras-chave: pós-fordismo, empreendedorismo urbano, classes criativas.

Abstract: In this paper I question the general forms of contemporary management of large cities, its relationship to the means of capitalist spatialization and its articulation with the field of culture. Based on the assumption cyclical changes of the capitalist mode of production in its outlook unequal and combined, which is intended to outline the notion that significant changes are underway in order to represent and act on the city, and they show for problematizations culture, in particular with regard to labor and consumption. Thus, we intend to investigate the similarities between hegemonic contemporary urban planning and creative dimension of the market of symbolic goods. Finally, try to present ideas to incorporate part of the urban question in political investment which operates the dimensions of creativity.

Key Words: Post-Fordism, urban entrepreneurialism, creative classes

1. Professor Assistente do Curso de Graduação em Produção Cultural da Universidade Federal Fluminense (UFF). Mestre em Políticas Públicas e Formação Humana pela Universidade do Estado do Rio de Janeiro e Doutorando em Planejamento Urbano e Regional pela Universidade Federal do Rio de Janeiro.

Latitude, vol. 6, n², pp.191-217, 2012

DOI: https://doi.org/10.28998/2179-5428.20120207 


\section{Marketing urbano e a dimensão da criatividade: colonização iminente do capitalismo flexível?}

1 - Introdução: passagem do fordismo ao capitalismo flexível: leituras iniciais da teoria econômica.

Os usos do espaço são historicamente determinados pelos modelos de organização social e econômica que dialeticamente conformam as sociedades. Como um ambiente clivado por contradições e antagonismos, o processo de diferenciação espacial seria "uma decorrência ou projeção da forma pela qual se processa a divisão social do trabalho em uma determinada sociedade" (SCHNEIDER, 2009). Assim, o espaço expressaria as características da organização social, apropriados e gerenciados pelos meios de reprodução da vida material.

A formação social histórica assenta-se em um território, impondo - como ponto de partida material ao processo de acumulação - papéis determinados às regiões em termos de um esquema de divisão social territorial do trabalho, confinando setores especiais da produção em regiões especiais de um país, tal como conjuntos especializados (BREITBACH, 1992). Por conseguinte, as diferentes fases de expansão e desenvolvimento cíclico do capital expressam diferentes etapas no modo de apropriação do espaço. Acentua-se aqui duas fases que associam diversas transformações na esfera da produção; o fordismo e a acumulação flexível.

A fase monopólica do capital é marcada pelo surgimento e prevalência dos grandes conglomerados produtivos. Essa concentração e centralização alteraram as formas de concorrência em relação à fase anterior, que passa a ser exercida entre grandes blocos de capital, com enorme capacidade de diversificação e financeirização. Seu processo é iniciado, nos países capitalistas avançados, no fim do século XIX, difundindo-se plenamente no Pós-Guerra (MELLO, 1998; BOLAÑO, 2000).

Os traços característicos desta fase do capital têm como acento o modelo de acumulação "fordista", que prevaleceu durante os "30 anos gloriosos" de sua expansão. Sustentado por altas taxas de investimento, o fordismo foi capaz de empregar alto número de mão-de-obra e de articular a partilha parcial dos ganhos de produtividade com as camadas assalariadas. Esta etapa de desenvolvimento do capitalismo apoiou-se em um processo bipartite: a base de concentração e centralização dos investimentos de capitais, que proporcionou o surgimento das grandes organizações empresariais; e a forte intervenção do Estado nas economias nacionais; associando a estabilização do processo de produção ao conjunto de intervenções propostos por Keynes (HARVEY, 1993). Para assegurar o crescimento sustentado, com taxas de lucro relativamente moderadas e progressivas, as corporações comprometiam-se com "processos estáveis, mas vigorosos de mudança tecnológica, com um grande investimento de capital fixo, melhoria da capacidade administrativa na produção e no marketing e mobilização de economias de escala mediante a padronização do produto" (HARVEY, 1993: 129). 
João Domingues

O papel do Estado era exercido sob um grau de envolvimento ativo, combinando apropriadamente políticas fiscais e monetárias, com forte aporte de investimentos na área de transportes e equipamentos (HARVEY, 1990). A condição para o "fornecimento de bens coletivos dependia da contínua aceleração da produtividade do trabalho no setor corporativo", capaz de manter o Estado keynesiano "fiscalmente viável" (HARVEY, op.cit.: 133). Os fatores principais da crise do regime fordista determinaram, em grande parte, a reorganização do sistema de produção capitalista. Dois, são os primordiais: a primeira crise de superprodução e de superacumulação, depois da Segunda Guerra Mundial, após 1973, gerando forte onda inflacionária (HARVEY, 1993); e a reconstrução das bases econômicas de um capital financeiro, que operou forte limitação aos gastos do Welfare State.

O período em questão, marca o encerramento dos 'trinta anos gloriosos', expondo o caráter cíclico de expansão e crise do modo de produção capitalista, bem como a necessidade de reestruturação econômica e seu rebatimento sobre a questão territorial. Findo o período de taxas elevadas de crescimento e da melhoria das condições de consumo dos trabalhadores, arbitra, por conseguinte, a noção de que permanece em curso a disputa pelo sentido das mudanças, após a crise do Welfare, da hegemonia das políticas keynesianas e da redefinição do papel do Estado-Nação na regulação da economia.

Dadas as condições sócio-históricas na determinação estrutural da reprodução da vida material, a crise da fase fordista revela a grande complexidade das transformações correntes (o estabelecimento de novos paradigmas tecnológicos e as alterações dos níveis de processo e produção, o deslocamento geográfico das atividades produtivas, a reafirmação da dominância financeira, e a renovação do aparato político-institucional), apresentando a reposição das melhores condições possíveis para a regra geral de valorização do capital. A transição cíclica do capital pode ser interpretada por diversas correntes da teoria econômica, valendo neste trabalho a contribuição da Escola Francesa da Regulação².

A Escola da Regulação (ER) opera uma abordagem que sintetiza o regime de acumulação - a organização da atividade produtiva - e o aparato regulatório como parte de um mesmo processo histórico de superação interna das crises cíclicas do capital. A proposta mais nuclear da ER consiste em elaborar uma concreção histórica do capital, valorizando categorias de mediação capazes de periodizar o capital em sua totalidade, evitando a sobrelevação ora de um polo empírico, ora de um polo abstrato. As três mediações essenciais seriam as formas institucionais, os regimes de acumulação e o modo de regulação.

${ }^{2}$ O núcleo mais representativo da Escola da Regulação conta com Michel Aglietta, Robert Boyer, Alain Lipietz e Jacques Mistral. 


\section{Marketing urbano e a dimensão da criatividade: colonização iminente do capitalismo flexível?}

Acerca das formas institucionais, a ER busca deter-se sobre os procedimentos sociais que regulam e conferem legitimidade aos compromissos que os agentes aderem para a reprodução da vida econômica e social; sejam eles as relações salariais, monetárias ou a ênfase do papel do Estado no estabelecimento das normas de relação econômica. Estes procedimentos podem tornar-se historicamente obsoletos, sendo, assim, substituídos, para a continuidade do desenvolvimento do sistema. O regime de acumulação pressupõe a atuação de formas de regulação, e é a determinação histórica do modo de produção capitalista e da valorização do capital (POSSAS, 1998). A tipologia de referência ao período marca a transição entre a acumulação intensiva com consumo de massa (fordismo) para a acumulação intensiva com consumo diversificado entre massa e nicho (pósfordismo).

O modo de regulação compreenderia uma superestrutura, assegurando a reprodução das relações sociais em sentido amplo, e assegurando as formas de regulação do conjunto do sistema, mesmo sob seu caráter contraditório. Refere-se a uma "compatibilidade de comportamentos dos agentes no quadro do regime de acumulação" (POSSAS, op.cit.: 196). Para a análise da etapa de possível saída da crise, a ER propõe uma descaracterização no modo de regulação monopolista (fordista) e o esgotamento de suas formas institucionais. Tratar-se-ia, portanto, de formular a natureza da captura de um novo regime de acumulação e de seu modo de regulação. Neste sentido, as atenções recaem especialmente sobre "as relações imediatas de produção (organização do trabalho) como o conjunto de relações socioeconômicas (relações macroeconômicas: distribuição, consumo e investimento)" (POSSAS, op.cit.: 205).

A transição do padrão fordista-taylorista para o que Harvey (1993) denomina "acumulação flexível" implica na reconfiguração total das forças produtivas, sob a desintermediação do sistema financeiro, deslocalização das estruturas territoriais de produção e reorganização do sistema produtivo. A passagem ao pós-fordismo marca uma transição entre o regime de acumulação e o modo de regulamentação a ele associado, buscando substituir a rigidez produtiva por uma maior flexibilidade de processos, mercados e trabalhadores. Traduz-se em novos cenários de desemprego estrutural, desregulamentação da legislação do trabalho, ampliação do emprego temporário e terceirização (HARVEY, op.cit).

Caracteriza-se, ainda, pelo "surgimento de setores de produção inteiramente novos, novas maneiras de fornecimentos de serviços financeiros, novos mercados e, sobretudo, taxas altamente intensificadas de inovação comercial, tecnológica e organizacional" (HARVEY, op.cit: 140). O empenho em uma série mais diversificada de produtos corre lado a lado com a desconcentração espacial das indústrias em plano mundial. $\mathrm{O}$ trabalho organizado no fordismo foi "sendo substituído por uma reconstrução de focos de acumulação flexível em regiões que careciam de tradição industriais anteriores" (HARVEY, op.cit: 140), reorganizando 
as estratégias e marcos da produção espacial, contando com trabalhadores adaptáveis e, quando necessário, "geograficamente móveis". As economias de escala de massa do período fordista foram sendo substituídas por uma "crescente capacidade de manufatura de uma variedade de bens e preços baixos em pequenos lotes" (HARVEY, op.cit: 148), ampliando sua capacidade de dispersão geográfica e de busca de mercados de perfil específico.

\section{A flexibilização como gestão das cidades.}

A transição da fase monopolista para a acumulação flexível e a transformação dos fatores macroeconômicos globais geraram significativas transformações na relação entre os processos organizados do trabalho e, especialmente, nos estudos e na concepção gerencial sobre a urbanização. A progressiva desindustrialização urbana, o crescimento estrutural do desemprego e a capacidade declinante dos Estados-Nação em controlar os fluxos financeiros de empresas multinacionais estabeleceram as condições concretas para a efetivação de um novo modelo de governança e planejamento das cidades e de sua forma de universalização para os processos mais recentes de produção do espaço urbano.

Para consolidar-se em plano mundial, foi necessário imprimir ao período uma série de mudanças radicais, no conjunto de categorias enunciadas pelos atores que procuram ocupar posições predominantes na enunciação de discursos e na construção dos modelos referenciais da gestão urbana. Desta forma, as estratégias discursivas acionadas após a década de 1990 procuraram anunciar uma inadequação dos sistemas urbanos e de seus modelos de planejamento aos desafios de um mundo globalizado, bem como as alternativas para as saídas da crise anunciada, tendo como solução a adequação e valorização de características urbanas "mundializadas" (COMPANS, 2004).

A construção desta nova concepção discursiva tem como nexo emissor o ideário neoliberal e seu léxico, baseado na eficácia de gestão, privilegiando as abordagens "administrativas" e "eficientes" da cidade ao criticado burocracismo dos Estados-Nação e de seu "planejamento centralizador". Dão lugar a formas de intervenção "empreendedoras", igualmente flexíveis quanto à "multiplicidade de polos de iniciativa e decisão, envolvendo atores não-governamentais, semipúblicos e privados" e na dinâmica de promoção "dos mecanismos de negociação das normas urbanísticas, liberação do controle do uso do solo, renúncia fiscal e subsídio ao investimento privado, mediante a oferta de infraestrutura, terrenos, formação de mão-de-obra etc (ACSELRAD, 2004).

A forma de negociação com o capital financeiro internacional, cada vez mais disperso territorialmente, interferiu na produção da agenda pública e na postura dos governos locais. Como contradição à dispersão geográfica das grandes empresas, bem como à ampliação das trocas comerciais e à proliferação dos 


\section{Marketing urbano e a dimensão da criatividade: colonização iminente do capitalismo flexível?}

mercados de capitais financeiros e fictícios, as mudanças introduzidas pelas novas formas de controle de processos produtivos, funções de comando, controle e inovação estariam sendo perseguidos pela fixação das matrizes corporativas nas grandes cidades, quando estas puderem oferecer "determinadas externalidades essenciais à sua realização, como modernas infraestruturas de transporte e telecomunicações e recursos humanos altamente qualificados" (COMPANS, op.cit: 37).

Capturada, de forma geral como empreendedorismo urbano ${ }^{3}$ (HARVEY, 1993), este novo processo se caracteriza por um "padrão de conduta na governança urbana que combina poderes estatais (local, metropolitano, regional, nacional ou supranacional), diversas formas organizacionais da sociedade civil (câmaras de comércio, sindicatos, igrejas, instituições educacionais e de pesquisa, grupos comunitários, ONGs, etc) e interesses privados (empresariais e individuais), formando coalizões para fomentar ou administrar o desenvolvimento urbano", dependente das condições locais e das alianças forjadas para o projeto (HARVEY, 2006: 230).

Estas formas "empreendedoras" de ação sobre o espaço urbano reivindicam uma novíssima supremacia dos governos locais em relação aos Estados Nacionais na "promoção das condições de produtividade e competitividade das empresas localizadas em seu território, e à capacidade de representação e legitimação políticas" (COMPANS, op.cit: 31), sugerindo que os governos locais teriam posições privilegiadas na negociação com as empresas transnacionais e suas matrizes financeiras na integração aos sistemas urbanos. $\mathrm{O}$ argumento central para esta mudança assinala a necessidade de atração e manutenção dos capitais financeiros e móveis e das matrizes de empresas multinacionais. O desenvolvimento econômico em larga escala demandaria a participação orientada dos governos locais, com pacotes substanciais de incentivo e diminuição dos riscos de investimento ao capital:

Seja na inversão direta de recursos na modernização da infra-estrutura urbana, seja na elisão de constrangimentos de natureza legal ou burocrática à valorização dos capitais privados -, à participação crescente do setor privado na gestão de serviços e equipamentos públicos, à busca de construção de consenso social em torno de prioridades "estratégicas" de investimentos (COMPANS, op.cit).

\footnotetext{
${ }^{3}$ Segundo Compans, as concepções sobre as novas formas de relacionamento entre capital e espaço urbano e seu modelo específico de gestão são interpretadas sob diferentes categorias: denominado por Harvey de "empreendedorismo urbano", por Ascher de "gerenciamento público urbano", por Le Gàles de "governança urbana", entre outros; "a multiplicidade de denominações atribuídas ao mesmo modelo corresponde à ênfase que cada autor confere às características interpretadas por eles como essenciais" (Compans, op.cit). A preferência pelo modelo descrito por Harvey se dá por sua interlocução explícita com o campo cultural.
} 
O apelo à racionalidade empresarial constrói as condições de mudanças na administração pública, tanto no desenvolvimento racional planejado, quanto na postura mais ativa das cidades na promoção do desenvolvimento econômico. Desta forma, os governos locais constituem-se como novos atores globais, no papel de apoiadores de empreendimentos privados, ou ainda, de forma direta na criação de novos empreendimentos; fazendo "parecer como se as "cidades" pudessem ser agentes ativos quando são simplesmente coisas" (HARVEY, 1993:169).

A reificação da cidade como um agente realiza, portanto, uma dada concepção de ajuste entre um novo regime de acumulação e um novo modo de regulação para o plano urbano, permitindo "esconder os verdadeiros atores sociais interessados nos projetos urbanos" e contribuindo "para a dissolução de possíveis contraposições ou resistências" (SANCHEZ, 2010: 428). Tal como no controle dos fluxos financeiros, o Estado-Nação tem seu papel reduzido e os governos locais se tornam o elo entre os fluxos globais e os setores produtivos urbanos (ACSELRAD, op.cit.). A renovação da cidade, ela mesma como uma mercadoria, e da economia, no plano urbano, ganham dimensão competitiva, em plano internacional. De forma geral, as políticas do Welfare, já desmanteladas ou constrangidas, e as possibilidades de gerenciamento da cidade passam a depender do crescimento constante da entrada e da permanência de capitais e da geração dos empregos a ele associados.

Esta racionalidade empreendedora não apenas impõe transmissões das funções dos Estados-Nação às municipalidades, mas constitui, em especial, a substituição radical da perspectiva de convivência e futuro comum da socialidade citadina pelo heurismo pragmático da administração empresarial e pela infalibilidade de seu discurso competente. Encolhe-se, desta forma, o espaço de atuação dos cidadãos e sua diversidade de problematizações para que os managers e players - os sujeitos dotados das competências mais adequadas para o empreendimento no espaço urbano - possam gozar de seus atributos para definir as condições de interferência no uso público do planejamento.

Desta forma, as cidades tornam-se empreendimentos muito especiais de comercialização de mercadorias únicas, transformando seus "atributos locacionais" e suas "qualidades urbanas" em commodities de extremo valor ao capital transnacional, para que o espaço urbano - este, a sua principal mercadoria ativa - e a oferta de seus trabalhadores especializados em serviços avançados possam ser expostos como um bom atrativo para os negócios. Para que o processo seja eficiente, utiliza-se de uma plêiade de mecanismos discursivos. "na qual a cidade torna-se "empresa", equipamentos, serviços e trabalhadores tornam-se "mercadorias", e a competitividade de empresas torna-se "competitividade da cidade" -, como um recurso discursivo pelo qual atribuem novos papéis e objetivos à administração pública" (COMPANS, op.cit:27). 


\section{Marketing urbano e a dimensão da criatividade: colonização iminente do capitalismo flexível?}

Cabe à produção da gestão empreendedora sobrepor a construção da racionalidade empresarial, sintetizada na eficácia administrativa sobre a noção de "bem comum", que o Estado condensava e salvaguardava. Ao aplicar-se à dimensão territorial, deslocando a dimensão da garantia das instituições de promoção e defesa da cidadania como função primordial da estrutura política e valorizar a dimensão do desenvolvimento, constrói - via Estado "uma fusão entre as noções de "interesse público" e "interesse privado" (COMPANS, idem).

Para tal, esta concepção de planejamento reposiciona a questão urbana, de "temas como crescimento desordenado, reprodução da força de trabalho, equipamentos de consumo coletivo, movimentos sociais urbanos, racionalização do uso do solo", para um novo tipo de problemática urbana que tem "como nexo central a problemática da competitividade urbana." (VAINER, 1999, 2000). Em suma, o "ordenamento do espaço baseado no padrão universalista de intervenção sobre o urbano", orientado para "o resgate da função social da cidade, que marca o enfoque regulatório clássico" é colonizado pelos padrões de competição internacional entre cidades e para a atração de investimentos financeiros (SANCHEZ, 1997).

Harvey remete a uma distinção essencial ao modelo empreendedor de cidade entre 'governo' urbano e 'governança' urbana, quando “o poder real de reorganização da vida urbana muitas vezes está em outra parte, ou pelo menos, em uma coalizão de forças mais ampla, em que o governo e a administração urbana desempenham apenas um papel facilitador e coordenador" (HARVEY, 2006: 171). Desta feita, para capturar de forma geral a forma de gestão do empreendedorismo urbano, seria necessário compreender a formação da política de coalizão em plano urbano - necessária para a implementação de gestão empreendedora - que se realiza na formação de alianças de classes, em ambientes extremamente complexos, de forças mobilizados pelos distintos agentes dispersos no espaço social.

Como o interesse central do empreendedorismo urbano visa a adequação da gestão urbana a um determinado mercado de cidades globais, lutando por investimentos, por certo esta dimensão só se realiza em um complexo circuito internacional de interesses na acumulação urbana. Os agentes mais importantes deste conjunto têm no descolamento do capital financeiro das atividades produtivas seu principal nexo intermediador. Tratam-se de "empresas de consultoria em projetos, pesquisas, arquitetura, de produção e consumo dos serviços turísticos, empresas bancárias e financeiras especializadas no crédito imobiliário, empresas de promoção de eventos" que, em conjunto com os atoreschave locais, articulam os recursos e os fundamentos técnicos para legitimar tanto o projeto de competição urbana quanto as próprias coalizões urbanas (RIBEIRO, 2010).

Para adequar-se, a gestão pública deve transformar-se com alguma radicalidade, recrutando operadores identificados com o universo gerencial técnico 
da administração privada. Este recrutamento impõe uma suposta eficiência administrativa privada à gestão pública da cidade, em geral abandonando ou desvalorizando sua organização burocrática. Tratados como "bolsões de gerência técnica", estes novos órgãos condensam competências que para seu pleno funcionamento necessitam de um alto grau de insulamento burocrático, diretamente vinculados aos chefes do executivo (RIBEIRO, op.cit).

Esta mobilização é facilitadora das estratégias de naturalização discursiva e mercado-técnica da cidade, e, de forma geral, são estas alianças mobilizadoras da coalização urbana que permitem realizar a transição para a gestão empreendedora das cidades. Como um projeto tornado genérico, as cidades constroem suas políticas urbanas sob um conjunto bastante restrito de ações, em geral, baseadas em torno da atração de eventos internacionais de grande repercussão e da regeneração de áreas urbanas degradadas, prioridades que permitem ao mesmo tempo "legitimar as elites políticas na coalização e no projeto empreendedor" e "construir as alianças com os interesses do complexo internacional de entretenimento" (RIBEIRO, 2011).

Como a governança para o empreendedorismo urbano depende de uma certa pactuação entre setor público e agentes privados, deve-se levar em conta que as características de cada território irão determinar qual o projeto de cidade virá a ser perseguido. Este registro é essencial para entender que o empreendedorismo urbano tenta se apresentar como uma forma de generalização da organização da gestão urbana, mas seu êxito é diretamente conectado às características particulares de uma cidade - tornadas mercadoria distintiva - que são acionadas para que seu modelo de gerenciamento possa ganhar forma. Cabe, aqui, realizar uma diferenciação mínima quanto às possibilidades de atração entre investimentos e indivíduos consumidores e indivíduos trabalhadores, essencial para compreender como a generalização do empreendedorismo urbano se conecta ao campo cultural e às políticas culturais.

Com o declínio do setor secundário na crise do fordismo, uma massa de trabalho vivo é deslocada para o setor de serviços, cada vez mais tecnicamente baseado nas atividades ligadas à digitalização de informação e pelo barateamento dos custos de dispositivos comunicacionais (CLARK ET ALL, 2002). As mudanças no campo do trabalho, oriundas das novas tecnologias de comunicação, produziram um cenário bastante diferenciado de integração dos trabalhadores no espaço urbano. Se as cidades industriais perderam capacidade de planejamento e conexão após a flexibilização e dispersão produtiva do capital, os grandes núcleos urbanos americanos e europeus - por seus equipamentos de serviços dos mais diversos tipos e alto investimento em economia de informação - permaneceram como o centro das matrizes financeiras de grandes empresas. Como tal, reúnem condições de atração de uma classe trabalhadora muito peculiar, com alto grau de especialização educacional e rendimentos salariais muito elevados, que se 


\section{Marketing urbano e a dimensão da criatividade: colonização iminente do capitalismo flexível?}

posicionaram nas transformações do capitalismo flexível entre o setor financeiro e o de alta tecnologia.

Pela lógica de dispersão geográfica do capitalismo flexível, o nível de distinção do projeto de coalizão urbana se determina também pela capacidade de atração de uma novíssima classe de sujeitos menos dispostos à fixação territorial, já que a lógica salarial destes grupos acompanha a lógica de dispersão financeira atual, Portanto, os interesses desta classe trabalhadora, traduzidos como "qualidade de vida", serão o tom distintivo do investimento do empreendedorismo urbano na produção do espaço urbano e no fornecimento de serviços pessoais orientados a reboque de um certo um certo tipo de refinamento estético. As práticas de consumo estendidas ao consumo do espaço nestas cidades têm como nexo causal a preocupação com a estilização da vida destes consumidores ativos, diretamente identificados com as classes médias e altas (CLARK ET ALL, op.cit). Por outro lado, existem cidades com dinâmicas de produção menos densas. Estas precisam introduzir ao seu planejamento empreendedor um certo número de propriedades diferenciadas para atração de uma classe de interessados mais ligados ao gasto econômico imediato que com sua fixação territorial. Quanto à atração de capitais, o desempenho de seu projeto empreendedor liga-se, de forma mais endêmica, à indústria do turismo.

Nesta medida, impõe-se uma qualidade de variações à apreciação do empreendedorismo urbano como um projeto. Tomando a questão para o campo cultural, a associação à gestão empreendedora variará conforme as condições concretas de produção capitalista do espaço, em especial na complexa dinâmica entre trabalho e consumo, baseada na coalizão urbana que organiza seu projeto de gestão. Por óbvio, esta associação cultural do empreendedorismo urbano provoca rebatimentos para o campo das políticas culturais. Este é um aspecto central para pensar as políticas culturais em plano urbano, no período pós-fordista. Ao ser capturada pelo universo empreendedor da cidade, a cultura pode operar como um simples mecanismo de legitimação da coalizão urbana, podendo estabelecer uma certa tendência instrumental de redução de sua construção normativa e de seu vínculo às dimensões mais amplas da questão urbana, reproduzindo, assim, o acento mercado-técnico das condições de reprodução urbana.

\section{Classes criativas e marketing urbano. Domínio ideológico pleno do capitalismo pós-fordista?}

Como a problemática urbana do empreendedorismo implica na contenção do capital financeiro e na geração constante de empregos urbanos agregados à estruturação do espaço, a cultura se mostra uma peça fundamental para seu projeto. Torna-se essencial pontuar uma discussão entre as dimensões urbanas das políticas culturais e as formas de construção cultural nas políticas urbanas 
empreendedoras. Este registro pode ser capturado de diversas maneiras, mas prefere-se trabalhar aqui com as dimensões do marketing urbano e aquelas derivadas da recente discussão sobre criatividade. Para atender a um empreendimento de tamanha monta no espaço urbano, os articuladores deste processo precisam recorrer a um elenco de categorias que tenham uma extensão capaz de organizar tanto as mudanças no campo do trabalho, os agentes propensos a ocupar novas oportunidades de emprego e mesmo a naturalizar processos sociais de integração destes agentes na complexa conexão entre o trabalho cultural e a necessidade de atração de capitais financeiros, no âmbito urbano.

As concepções de economia criativa, cidades criativas e classes criativas respondem a este desafio. São capazes de, ao mesmo passo, reivindicar e naturalizar as profundas mudanças da produção do urbano no período flexível do capital, estimular o posicionamento de agentes em novos postos de trabalho, criados em função das mudanças tecnológicas da microeletrônica e operar intervenções na organização espacial, traduzida em enclaves urbanos direcionados para a visitação turística ou para o agrupamento territorial de pequenas e médias empresas cujo vínculo é a produção simbólica.

É possível verificar, durante a última década, um aumento bastante relativo nas publicações que tratam do assunto (MIGUEZ, 2007), tendo sido incorporado, na pauta do Ministério da Cultura do Brasil, em algumas instâncias municipais e em outros organismos ligados ao setor privado. Desta maneira, o tratamento dado ao tema da criatividade não se mostra, aqui, como esgotado, podendo ser interpretado sob matrizes teóricas diversas e ainda em desenvolvimento. Interessa, neste momento, demonstrar como a literatura que trata da noção de criatividade se aproxima do empreendedorismo urbano. Nesta dimensão, dois autores são essenciais, Richard Florida (2002, 2005) e Charles Landry (1995).

A concepção de economia criativa é tratada como uma novidade no que toca à organização da cultura. Concebida em meados dos anos 1990 pelos governos Britânico e Australiano e adotada por organismos multilaterais - Conferência das Nações Unidas sobre Comércio e Desenvolvimento (UNCTAD), a Organização Mundial da Propriedade Intelectual (OMPI), o Programa das Nações Unidas para o Desenvolvimento (PNUD), Banco Mundial, Banco Interamericano de Desenvolvimento (BID) -, tem sido um parâmetro para o desenvolvimento de um conjunto de políticas voltadas ao incremento de atividades relacionadas ao universo cultural.

A ideia de economia criativa procura traduzir as atividades que "têm sua origem na criatividade, habilidade e talento individuais e que têm um potencial para geração de empregos e riquezas por meio da geração e exploração da propriedade intelectual" (MIGUEZ, 2007). Seu conteúdo central é, portanto, a ideia de propriedade intelectual traduzida de forma direta como "patentes, marcas registradas, desenhos industriais, indicações regionais e direitos autorais" (REIS, 


\section{Marketing urbano e a dimensão da criatividade: colonização iminente do capitalismo flexível?}

2012: 13). A primeira referência da concepção de criatividade como um capital econômico tem como primado a política do New Labor de Tony Blair, em 1997. Blair "embasou sua plataforma política na transformação do país para o que viria a ser a Creative Britain: um reino que poderia recuperar parte de sua supremacia econômica ao se transformar no polo criativo do mundo" (REIS, op.cit: 14). Para tanto, o Partido Trabalhista Britânico organizou um grupo de especialistas, "representantes referenciais do setor privado" e "instâncias governamentais", para identificar "uma lista de setores que se mostravam mais promissores para a economia nacional e concedeu a eles benefícios econômicos, culturais e sociais" (REIS, op.cit: 12). A estas dinâmicas produtivas muito diversas foi dado o nome de indústrias criativas ${ }^{4}$.

A dimensão da economia criativa desenvolvida no New Labor pouco a pouco inunda o uso de gramáticas de uma série de outros governos e instituições acerca da cultura e do desenvolvimento na fase flexível do capital. A diferença fundamental é que cada país parece criar para si uma certa canastra de setores que são diretamente identificados com a natureza das atividades ligadas à propriedade intelectual natas ao lugar de origem. De certa forma, a economia criativa, como uma referência expandida além do terreno britânico, trata muito mais do reconhecimento nacional ou local dos agentes produtores e da tipologia de setores que serão incentivados. Cumpre, de início, um papel de renovação no fomento e promoção de um conjunto de atividades de trabalhadores especializados, que podem se conectar tanto às formas mais populares de produção cultural como às práticas oriundas de atividades do capitalismo flexível.

Apenas na década de 2000, após o aumento de demanda por produtos intangíveis como softwares, música e suportes virtuais para conteúdo literário e visual, a economia criativa passa a ser tematizada fora dos gabinetes de governo, por agentes representantes de empresas de consultoria em planejamento. Tal como no empreendedorismo urbano, o processo em questão torna os consultores em economia criativa na principal referência para os governos nacionais e municipais. Esta concepção simplificada de economia criativa, tratada muito mais como um guia para transformações da economia, recebe uma gama mais considerável de mediações quando transportada à ideia de cidade criativa e de classes criativas.

Embora tenha surgido na literatura da área posteriormente às categorias ligadas ao urbano, a concepção de classes criativas, reivindicada por Florida (2002), tem recebido atenção de cientistas e administradores urbanos nos Estados Unidos e

\footnotetext{
${ }^{4}$ Foi apresentado um conjunto de 13 áreas "desde artes, artesanato, folclore, patrimônio (o que há de mais anímico em uma cultura), passando pelas indústrias culturais e incorporando ainda alguns setores que mantêm uma relação bastante próxima à cultura para se devolverem, tais como a moda, o design, a arquitetura, a propaganda e o setor de lazer" (REIS, 2012: 13).
} 
João Domingues

Europa (KRÄTKE, 2012; PECK, 2010). A concepção de Florida está baseada em uma diferenciação do mundo do trabalho sob quatro categorias principais: as classes trabalhadoras industriais, as classes que reúnem um quadro de competências menos habilidosas do setor de serviços, a classe ligadas às atividades da agricultura. A última classe é a designada como criativa, que na opinião do autor, seria hoje o grupo decisivo para o desenvolvimento econômico (FLORIDA, op.cit).

Neste primeiro momento, Florida não se ocupa em estabelecer diferentes limites às atividades imateriais que se vinculam de forma exponencial ao setor industrial, que agrupa sujeitos que executam tarefas cada vez mais combinadas entre formas intelectuais e primárias de produção (KRÄTKE, op.cit). Para Florida, as classes criativas seriam compostas de três grupos ocupacionais: o núcleo supercriativo, que contém cientistas naturais e engenheiros, cientistas da informação, economistas e cientistas sociais, profissões médicas, arquitetos, staffs acadêmicos. O segundo grupo é chamado de boêmios, composto por grupos ocupacionais da esfera da arte e entretenimento. O terceiro grupo é denominado profissionais criativos, composto por empregados de alta qualificação técnica tais como gerentes, experts em organização, consultores de negócio, mediadores em administração, corretores (brokers), profissionais de finanças, membros de corpos legislativos, funcionários políticos, e gerentes de administração pública.

Já em sua concepção taxonômica, Florida classifica sob a mesma rubrica grupos ocupacionais engajados em atividades muito diferentes em sua dimensão produtiva, apostando em conceito muito vago para compreender um grupo heterogêneo de trabalhadores. $\mathrm{O}$ processo mostra-se, assim, altamente problemático ao ocupar-se de uma mesma categoria geral para imprimir uma característica distintiva - a criatividade - para atividades de desenvolvimento econômico e criações artísticas envolvidas na economia da cultura, desenvolvimento tecnológico e atividades identificadas com os "profissionais criativos" (KRÄTKE, op.cit). Ao fazê-lo, Florida imprime uma naturalização das contradições contemporâneas do mundo do trabalho e uma elevação da concepção de criatividade a atividades que são imediatamente identificadas ao descolamento produção-financiamento e seus agentes operadores. Ao identificá-los como "criativos", Florida estabelece também uma certa naturalização de um discurso ideológico ligado ao modo de vida e à gestão neoliberal (KRÄTKE, op.cit).

Na concepção do autor, os agentes do regime contemporâneo de dominação financeira continuam criando "inovações" e "produtos" financeiros, sem que se espere que sua produção possa causar danos no desenvolvimento de setores da "economia real" (PECK, 2010). Dada a capacidade altamente volátil e destrutiva do mercado financeiro, a classificação de Florida denominada "profissionais criativos" tem uma tendência interna de alto apelo ideológico. Desta maneira, a teoria de Florida apresenta-se baseada em atribuições arbitrárias que suportam uma 


\section{Marketing urbano e a dimensão da criatividade: colonização iminente do capitalismo flexível?}

autoglorificação dos "líderes" ocupacionais do capitalismo contemporâneo (KRÄTKE, op.cit). Florida, porém, estende a caracterização de "profissionais criativos" à esfera da gestão pública. Quanto às considerações das atividades ligadas ao setor público, estando conectadas a este universo ideológico que é a substância das classificações de Florida, trariam um conjunto expressivo de apolitização das atividades e responsabilidades destes setores. Neste sentido, a criatividade suposta dos "profissionais criativos" atende por dentro do setor público às mudanças internas na administração urbana que permitiriam às cidades que recebem como seus moradores as classes criativas a perspectiva de um desenvolvimento econômico mais bem-sucedido.

Outra dimensão que deve ser apreciada é a construção do mercado de trabalho e a dimensão trabalhista. Os trabalhos que vêm predominando nas indústrias culturais são basicamente os de free-lancers, contratos temporários, e companhias de one-person-only (KRÄTKE, op.cit), absolutamente adequados ao maior responsável pelo crescimento dos empregos associados aos setores criativos. O setor privado prefere estabelecer estas relações empregatícias parciais, que beneficiam uma parte da classe dita criativa dos profissionais da economia da cultura. Nos países de economia capitalista mais desenvolvida, as indústrias culturais e de comunicação se caracterizam pela polarização entre trabalhadores flexíveis com "status privilegiado" e trabalhadores flexíveis situados em empregos altamente precários. A maioria destes trabalhadores tem que aceitar as condições de contratos de trabalho de curto período, horas excessivas de labuta e baixa remuneração. Traduz-se, desta forma, que a classe de trabalhadores ligados ao campo artístico e cultural se constitui em uma certa "classe média proletarizada do setor de serviços criativos" (KRÄTKE, op.cit: 142). Ademais, é possível questionar o caráter de generalização da noção de criatividade aplicada ao espaço urbano. O substrato mais significativo da gestão urbana organizada em torno da dimensão criativa seria a geração espontânea de recursos, criatividade social e ampliação de postos de trabalho. A desconfiança da causalidade imediata entre a geração das condições para a efetivação de "criativos" e a criação de novos empregos urbanos se mostra na ausência da discussão de Florida sobre a possibilidade de que cidades e regiões também alcancem sucesso sob perfis setoriais bastante diferenciados.

Desta forma, também é possível problematizar a dimensão altamente seletiva em termos espaciais da relação entre força de trabalho, ligada ao setor artístico, e sua concentração no espaço urbano, em uma estrutura internacional altamente concentrada ${ }^{5}$. É possível, portanto, pensar que apenas um número

${ }^{5}$ Isto implica na sujeição dos criadores e consumidores às regras do mercado, que vem destinando à participação dos países da América Latina na produção internacional da cultura apenas $5 \%$ dos ganhos, enquanto que Estados Unidos detém 55\%, a União Européia detém 25\%, e o Japão e a Ásia detém 15\% (CANCLINI, 2003). Sobre as importações, Japão, 
limitado de cidades e metrópoles pode fazer uso de suas indústrias culturais como focos de sua estratégia de desenvolvimento econômico. Recentemente, muitas cidades europeias, norte-americanas e sul-americanas com característica industrial desenharam "estratégias culturais" para sua regeneração econômica, incluindo o suporte para setores da economia da cultura e a extensão de facilidades para a construção de ambientes urbanos. Estas estratégias culturais podem atuar centralmente na regeneração urbana de antigas regiões industriais, mas funcionam mais como um reforço de sua imagem urbana do que como uma máquina de criação de emprego.

A perspectiva de Florida encontra ressonância no trabalho de Landry e Bianchini (1995). Os autores buscam explorar a dimensão da criatividade como uma possibilidade real de enfrentamento das crises que as cidades enfrentam na reorganização do capitalismo flexível. Landry atesta que um dos principais problemas das cidades é sua divisão "cada vez mais socialmente fragmentada, com seu mercado de trabalho rateado entre gestores bem remunerados, tecnólogos e profissionais especializados em direito transnacional e negócios, e funcionários menos qualificados, de baixa remuneração e com serviços de período parcial, muitos dos quais são mulheres ou de minorias étnicas".

A criatividade é vista como uma possibilidade pra enriquecer "as ciências duras do planejamento urbano", mobilizando "experiências de diferentes pessoas atualmente marginalizados em seu processo decisório". Esclarece que o livro é resultado "de um longo período de pesquisa e consultaria sobre os problemas e as possibilidades de cidades na Europa e proximidades", cidades que enfrentam a baixa de valor-agregado das velhas indústrias, instabilidades, crimes e insegurança e a dependência das indústrias do século XXI da "geração de conhecimento através da criatividade e inovação combinado com rigorosa sistemas de controle" (LANDRY e BIANCHINI, 1995: 12). Desta forma, o pensamento criativo seria a ferramenta para superar a rigidez do planejamento clássico, de maneira a abrir-se aos "complexos fenômenos que nem sempre podem ser tratadas de forma estritamente lógica". Para tanto, Landry atesta que os sistemas produtivos precisam romper com os tipos instrumentais de criatividade, apelando para um "tipo completamente diferente de criatividade, (...) capaz de sintetizar e para avaliar os impactos em diferentes esferas da vida, para ver de forma holística, para entender como as mudanças materiais afetam percepções, para compreender as ecologias sutis de nossos sistemas de vida e como torná-los sustentáveis".

Quanto à dimensão da criatividade requerida, o autor faz dois movimentos explicativos complementares. O primeiro é destacar a noção de criatividade da noção de inovação. Enquanto a criatividade daria conta dos "processos através do

Estados Unidos, Reino Unido e França concentraram 47\% dos negócios na década de 90 (ARIZPE E ALONSO, 2005). 


\section{Marketing urbano e a dimensão da criatividade: colonização iminente do capitalismo flexível?}

qual novas ideias são produzidas", a inovação seria "o processo através do qual são implementadas". Este movimento é importante, segundo o autor, para descrever cidades que podem ser criativas "sem que tenham as habilidades analíticas, avaliativas e financeiras para desenvolver soluções inovadoras". O segundo movimento descreve a dimensão propriamente expressa da criatividade nas interações dos sujeitos com o mundo. Para o autor, a criatividade seria ordenada nas áreas das artes, publicidade, ciência e comunicação, organização e gestão de negócios, subculturas jovens e movimentos coletivos. Transportado à esfera urbana, este movimento atende ao fato de que:

No momento, a maioria dos governos municipais tem se inspirado apenas por dois tipos de criatividade que são mais fáceis de entender e gerenciar: àqueles que demandam o gerenciamento de organizações e negócios e os da publicidade e comunicações, vistas sob o número cada vez maior de campanhas de city marketing implementadas (LANDRY e BIANCHINI, op.cit: 23).

Por sua condição profissional de consultor para políticas urbanas, o autor se mostra preocupado em construir as condições para as cidades se transformarem em ambientes criativos. De forma a mostrar-se inovador, Landry propõe uma certa quantidade de obstáculos a se remover para que as cidades possam criar um ambiente propício à criatividade. Acurando o princípio empreendedor, Landry descreve que a gestão das cidades é, em grande parte, executada "por funcionários públicos que devem responsabilidades aos eleitores. Isso retarda o ritmo de resposta aos problemas, que tende a ser mais rápido em empresas privadas". A solução para este obstáculo seria criar um modo de gestão mais aberto, "criando canais para fluxos de ideias criativas dos seus cidadãos", "assim como as melhores empresas aproveitam sua força de trabalho e seus clientes para boas ideias" (LANDRY e BIANCHINI, op.cit: 25). A segunda razão é a medição das regras públicas para o funcionamento da administração urbana. Este processo gera regras e regulamentos complexos de longa duração, que envolvem "permissões de planejamento, licenças e restrições de tráfego", e que criariam uma certa mentalidade burocrática resistente à mudança, impregnando toda a administração pública.

O autor também faz referência ao "jogo de competição interurbana", destacando que as cidades tendem a basear menos suas propriedades "em recursos naturais, localização ou a reputação do passado" e "mais na capacidade de desenvolver imagens atraentes e símbolos para projetá-las eficazmente". Se a economia criativa é relacionada com a dimensão individual, a cidade criativa não 
pode aparecer como outra coisa senão como reificada, capaz de desenvolver estratégias atrativas para a visitação ou moradia das classes criativas.

Outra referência essencial para a problematização da relação entre o novo urbanismo e a cultura é a dimensão do marketing urbano. Neste caso, a dimensão cultural se associa ao projeto do empreendedorismo de forma singular. Ainda que de forma esparsa e pouco problematizada, uma dada dimensão do desenvolvimento econômico dá relevância ao campo cultural como seu constituinte central. Como já destacado por alguns autores, em referência à economia criativa, a produção do espaço como mercadoria envolve também as competências na produção de suas representações (SANCHEZ, 2010). Tem-se a ideia de que para o empreendedorismo urbano mercado-técnico ser bem-sucedido existe uma dependência da criação de uma imagem positiva da cidade, que ressalte suas qualidades únicas e distintivas, que demandam, inclusive, um tipo de arquitetura adequada ao novo ambiente. Põem-se em foco algumas estratégias de regeneração urbana e valorização de regiões urbanas degradadas, sendo centrais para a atração de usuários urbanos interessados em novas formas de consumo cultural - estádios esportivos, centros de convenção, praças de entretenimento destinados à organização de espetáculos urbanos em base temporária ou permanente (HARVEY, 2006).

A imagem da cidade reflete as decisões sobre o que e quem deve ser visível e o que não deve ser. Dependendo de como são acionadas, as imagens produzidas sobre a cidade representam certa linguagem que opera ao mesmo tempo sua determinação e sua exclusão. As imagens produzidas nunca representaram os espaços reais da cidade. Antes, são reconstruções imaginadas, de pontos de vista específicos, da monumentalidade da cidade (ZUKIN, 2006). No âmbito das transformações materiais em curso, a cidade moderna, cujo lay out remontaria ao funcionalismo econômico, é questionada. Sua imagem, nova ou significativamente reivindicada como não-abandonada, é a fonte principal de seu capital simbólico. É a adequação ao processo de produção e reprodução das imagens e a saturação de signos na reprodução da vida social (JAMESON, 1996) impõe uma estetização da realidade e coloca em primeiro plano a importância dos estilos de vida (FEATHERSTONE, 1995: 122), que vinculam organicamente a relação complementar entre produção, distribuição e consumo na esfera de reprodução das formas capitalistas.

Como um projeto que se fia num certo aparato simbólico para se realizar, a imagética adequada ao projeto empreendedor está permeada por contradições. Parte destas contradições pode ser observada na tensa construção entre a imagem urbana como um aparato singular utilitário, e a necessidade de operar - ainda que aparentemente - este utilitarismo aberto à sua politização, para além da finalidade estrita de comercialização urbana. As mudanças fundamentais nas práticas sociais do consumo - que rompem com a concepção interiorizada do trabalho e do 


\section{Marketing urbano e a dimensão da criatividade: colonização iminente do capitalismo flexível?}

consumo, na conduta ascética voltada ao mundo interior como elemento de disposição das virtudes pequeno-burguesas (FEATHERSTONE, op.cit.) encontram no espaço urbano uma nova referência. No limite em que as cidades conseguem transmitir um certo capital simbólico coletivo ou, ainda, um certo tipo muito preciso de capital cultural (na forma de sua apresentação propagandística e know-how de ferramentas de planejamento; no número de unidades acadêmicas de arte, arte-vanguarda e trabalhadores especializados em serviços para o campo cultural; e na oferta de experiências eventuais, agregadoras, populares ou não), transformando-se, também, em centros e referências de produção e distribuição da cultura. A ênfase na preocupação estética na produção da cidade e nos estilos distintivos do consumo coloca em questão a lógica do consumo de massa referencial do capitalismo monopolista. Como condição concreta à renovação do capitalismo flexível na esfera do trabalho e da acumulação, a esfera do consumo renova as preocupações estetizantes dos estilos de vida. Encontra-se, de acordo com Featherstone,

Uma convergência adicional no processo de estilização e estetização da vida cotidiana, entre, de um lado, a popularidade dos estilos de vida artísticos e da representação e manifestação estilizadas, e, de outro, o desenvolvimento de uma série diferenciada e sofisticada de bens de consumo, atividades de lazer e experiências, que incorporam um elevado input de design, estilo e imaginário artístico e cultural da moda (FEATHERSTONE, op.cit.: 137).

É a mudança da ênfase funcionalista para uma certa ênfase culturalista que encontra terreno fértil no aumento recente pelo interesse de estilos de vida urbanos e na ampliação do mercado de bens e informações culturais. Estas novas formas de construção imagética para o consumo têm seus desdobramentos na produção do espaço, criando "nas cidades os chamados "espaços de renovação", cada vez mais homogêneos no mundo porque são moldados a partir de valores culturais e hábitos de consumo do espaço tornados dominantes na escala mundo" (SANCHEZ, op.cit: 47).

O processo de criação imagética da cidade em um lugar inovador, estimulante, criativo, e seguro para se viver ou visitar pode ser melhor analisado sob as novas ferramentas de marketing e nas dimensões de construção das marcas corporativas. A mudança no panorama das atividades de comunicação empresarial se insere na transformação do domínio das práticas de comunicação de um capitalismo de bens para um capitalismo de marcas (RUBIM, 1998). Esta transformação das marcas empresariais incidiu na transferência de anúncios publicitários "que continham 
informações sobre o produto deram lugar a outros que incorporam um imaginário mais frouxo, associado ao estilo de vida" (FEATHERSTONE, op.cit.:123).

A tipologia de construção referencial das marcas adequa-se a um processo de dupla dimensão: as características inerentes que o tornem uma mercadoria reconhecida e as condições de seu posicionamento em um mercado altamente sofisticado e segmentados de bens distintivos, tal como as nuances de mercado capitalista nos últimos 40 anos. O acento deste processo corresponde à lógica empreendedora e flexível, quando as marcas devem se tornar coisas de tamanha importância que necessitam conferir aos seus consumidores algo além do valor-deuso de seus produtos, distinguindo-se de outras marcas através de experiências sensoriais mais amplas.

Grande parte dos investimentos empresariais na propaganda e nas novas formas de gestão de marcas tem como interesse provocar modificações na relação entre empresas, mercadorias e consumidores, apostando na vinculação dos produtos às imagens dos indivíduos e suas preferências no âmbito da realização do consumo. Os investimentos diretos no financiamento à produção artística, aos esportes, aos projetos de assistência social e eventos públicos caritativos permitem às empresas consolidarem imagens corporativas distintas para públicos consumidores distintos (KLEIN, 2002). Em acordo com os novos manejos da propaganda empresarial e do marketing publicitário, a estruturação da comunicação de grandes empresas passa a focar sua atenção no direcionamento do fluxo de informações de imagens para os consumidores, para atrair uma certa dimensão subjetiva da consciência da marca; uma operação que desloca o "foco no produto" para o "foco no cliente" (KLEIN, op.cit), de tal maneira que um determinado produto atenda e maximize as expectativas e desejos "até o nível da personalização, se possível" (TASCHNER, 1999).

Tal como empresas que se comunicam por marcas, as cidades também são espaços de oportunidades de experiências para estes novos consumidores. A referência da cidade como uma empresa e do espaço urbano como uma mercadoria são adequadas às novas formas de produção capitalista e às novas formas de consumo (SANCHEZ, op.cit). O foco no cliente orientado ao espaço urbano é concebido "como lugar onde o privado se afirma, produzindo signos que parecem realizar desejos e fantasias de consumo moldados por valores da 'mundialidade'" (SANCHEZ, op.cit:49). Desta forma, animação e espetáculo são elementos essenciais à comercialização da cidade como um ambiente criativo e estimulante, onde a produção de imagens publicitárias da cidade está correlacionadas às recentes práticas de intervenção urbana (HARVEY, 2004; SANCHEZ, op.cit).

A transformação da cidade em mercadoria se completa e se realiza em sua lógica sob os meios de sua publicização, via marketing urbano. Demonstra, desta forma, a conexão dialética entre a imbricação real da produção do espaço e sua representação (LIMA JÚNIOR, op.cit.). As políticas de comercialização das cidades 


\section{Marketing urbano e a dimensão da criatividade: colonização iminente do capitalismo flexível?}

são promovidas nas mais diversas escalas, apoiadas "em estratégias de convencimento e de marketing desenvolvidas pelos governos locais junto a grandes empresas com interesses localizados" (SANCHEZ, op.cit: 91). Torna-se, portanto, uma política de difusão de discurso cuja tessitura simbólica é construída para tornar hegemônicas determinadas leituras sobre o espaço que se mostrem compatíveis com os anseios de seus potenciais consumidores ou cidadãos "solventes" (SANCHEZ, op.cit). Como as estratégias vinculadas de parte da literatura responsável pela consolidação da economia criativa, a ênfase imagética do empreendedorismo urbano recai sobre a destinação de um certo grupo de agentes econômicos, dispondo o espaço urbano para sua forma de consumo ${ }^{6}$.

Como são tomadas de intencionalidade, as representações exigidas pelo empreendedorismo urbano operam de maneira a ressaltar a mercado-técnica urbana como a identidade do lugar. De forma geral, baseiam-se na produção de imagens-síntese de parcelas da realidade urbana, mediadas por um processo de seleção da experiência coletiva mediante estereótipos e simplificações pragmáticas da vida social no espaço, realizado por algum tipo de trabalhador especializado; "publicitários, consultores em marketing, produtores culturais, conselheiros de comunicação e pesquisadores de mercado" como os agentes preferenciais. Como síntese imagética, sua função é fixar uma parcial visão de mundo produzindo signos de bem-estar e satisfação adequados às demandas de consumo orientado (SANCHEZ, op.cit). Estas novas experiências do mercado publicitário atingem diretamente o cenário urbano, quando as marcas empresariais se acumulam em ruas, centros culturais patrocinados ou pequenas esculturas de propaganda. Estas modalidades de espetacularização do espaço urbano pretendem "estimular a reinvenção da cidade e sua nova inscrição mundial pela via dos megaeventos ou dos grandes projetos urbanos" (SANCHEZ, op.cit: 17) e formam as bases políticas e culturais para a reestruturação urbana e para a criação de territórios atrativos para o reordenamento do fluxo de consumo cultural.

A produção de construção e constante reciclagem das imagens das cidades tomadas como "modelos" empreendedores, e colocadas em circulação em um mercado internacional competitivo entre cidades apresentam semelhanças entre si e se demonstram como desdobramentos das práticas políticas e dos processos materiais de ação sobre os arranjos espaciais. Quando incidem sobre a renovação da cidade, operam, em geral, sob a incorporação de estilos de vida referenciados a valores de uma sociedade urbana mundializada (SANCHEZ, op.cit). Tanto o

\footnotetext{
${ }^{6}$ Os principais meios técnicos adotados pelo marketing urbano são "cartilhas escolares, vídeos promocionais, fôlderes e releases publicitários, programas e projetos institucionais de valorização da identidade da cidade, artigos em periódicos nacionais e internacionais, páginas da web, programas de rádio, matérias na imprensa local, material publicitário e novelas em televisão" (Sanchez, 2010: 101).
} 
envolvimento visual quanto o discursivo apostam na representação de valores que lembram a modernização da "infraestrutura de telecomunicações e transportes, à competitividade, à eficiência na gestão urbana, à construção de sustentabilidade, civismo urbano e multiculturalismo" (SANCHEZ, op.cit:71), que relembrem uma cidade "boa para os negócios".

Competências imagéticas e discursivas que "se fixam nas escalas nacional e internacional como espaço condensadores, por excelência dos anseios das classes dominantes relacionados ao modo de vida e ao usufruto dos espaços renovados" (SANCHEZ, op.cit:88). São, portanto, valores orientados diretamente aos agentes econômicos privados ou determinados segmentos sociais de classes médias ou médias-altas, os principais beneficiários das novas condições de gestão urbana e reestruturação espacial e público-alvo preferencial dos mecanismos de marketing urbano.

Constrói-se, portanto, uma ponte cognitiva entre imagem, cidade e empresa, de tal forma que os atributos particulares da gestão privada de negócios sejam impulsionados na articulação entre as práticas políticas orientadas pelos especialistas do empreendedorismo urbano, suas formas próprias de administração e as benesses traduzidas na representação imagética. Os atributos necessários à efetivação do novo modelo de gestão urbana e sua fixação material nas cidades impõem-se por uma série de categorias de percepção e representação simbólicas em que os atores dominantes oferecem o espaço urbano por meio da linguagem que "celebra determinadas palavras-chave que reafirmam, pela repetição exaustiva, as receitas contemporâneas par as cidades" (SANCHEZ, op.cit:121). Representações que são também orientadas às práticas mais recentes do consumo turístico e a busca de consumidores nativos ou estrangeiros por espetáculos e bons serviços (criativos, inclusive). Envolvem a:

Seleção de partes da realidade urbana", incidem sobre propostas de preservação do patrimônio histórico e em projetos que "vendem representações de um viver urbano saudável, com padrões de qualidade de vida associados à cultura urbana contemporânea: múltiplas opções de lazer e cultura, meio ambiente equilibrado, trânsito fluido, espaços urbanos revitalizados, novas centralidades e variedades de espaços de consumo, tecnologias de comunicação avançadas, desenvolvimento econômico sustentável (SANCHEZ, op.cit: 33).

Impõe-se, portanto, a referência entre produção e disseminação de discurso e as formas ideológicas presentes nas seleções das imagens do marketing urbano, que, no limite, influenciarão nas práticas culturais dos diversos agentes sociais e na 


\section{Marketing urbano e a dimensão da criatividade: colonização iminente do capitalismo flexível?}

própria ação das políticas culturais, quando interessadas na produção e disseminação de conteúdos simbólicos. A produção das imagens se mostra, assim, como um processo extremamente complexo de luta simbólica que condensa a forma de apropriação e representação do espaço, que se expressa, em larga medida, nas relações de poder presentes nestas novas formas de gestão urbana. Como uma mercadoria, a estratégia de operação do city marketing procura fetichizar a experiência da urbanidade. A construção imagética e espetacular do marketing urbano assume uma forma de generalização de fragmentos da realizadade urbana, sob "redes de discurso de poder-verdade com pretensões de transformação em discurso único" (SANCHEZ, op.cit:79). A instrumentalização de aspectos culturais em nome da imagem da cidade retira ou escondem muitas das características concretas presentes nos processos materiais e históricos de reprodução urbana e dos sujeitos que participam de sua reprodução, incidindo nas agendas de políticas culturais.

Tomadas como representações oficiais da realidade urbana, as imagenssíntese que "são postas como dominantes em cada cidade onde está em curso um projeto de modernização urbana definido e explicitado, não deixam margem a dúvidas ou interpretações diversas sobre a informação que veiculam, não oferecem alternativas à sua decodificação" (SANCHEZ, op.cit: 108). Procuram mostrar-se, portanto, como fatos sociais inquestionáveis. São processos de seleção e edição da realidade que tendem a negar a "possibilidade de existência de outras imagens e de outras leituras" (SANCHEZ, idem, ibdem), e dos sujeitos cujas expressões pareçam conflitivas aos parâmetros da cidade empreendedora. Neste sentido, a produção do discurso-síntese se torna a enunciação dos interesses dominantes sobre a "cidade ideal" que construa um certo tipo de adesão social ao projeto empreendedor e que procure,

"a partir da difusão de "modelos", normatizar as cidades, configurá-las de acordo com os parâmetros da cidade competitiva, da cidade-empresa, da cidademercadoria, desconsiderando a complexidade socioespacial e a multiplicidade de projetos políticos em cada território urbano" (SANCHEZ, op.cit:130.).

\section{Qual agenda criativa seguir?}

De maneira geral, os processos e usos singulares da construção imagética urbana não são atribuídos ao quadro de competências da gestão identificada com as políticas culturais urbanas. Estes atuam, de forma externa e com relativa autonomia, por escritórios privados com competência técnica, instituições de cooperação multilateral ou por órgãos da gestão pública burocraticamente 
insulados, todos diretamente identificados com os projetos da coalizão urbana empreendedora e com acento na competição interurbana. Todavia, ainda que como aparentemente externos, o trabalho destes organismos podem incidir na determinação e no desenho das políticas culturais, quando supomos tanto a dimensão da disputa em torno das imagens quanto da transformação material urbana a que ela faz referência ou é dela derivada.

Neste sentido, a literatura crítica sobre o campo do city marketing aponta para um primeiro momento; uma relação geral de instrumentalização entre cultura, política da cultura e política de comunicação, identificada com arquétipos empresariais e como esta relação é essencial para dimensionar a publicização e legitimação dos projetos urbanos empreendedores.

Nesta primeira leitura, a cultura aparece de maneira simplificada, como um recurso para a implementação da mercado-técnica urbana. Se este projeto se mostrar o mais adequado para a concretude política da coalizão urbana, as políticas culturais podem apresentar-se de forma subordinada ao processo de transformação proposto pela gestão urbana. Esta verificação dependerá do lugar que a gestão cultural ocupa na administração pública e sua capacidade de interação e transversalização com outras políticas governamentais, e também na forma como os grupos sociais identificados com o campo cultural estabelecem suas estratégias de reivindicação, a dimensão espacial de suas lutas e seus meios de comunicação e ampliação de sua base social.

Portanto, a concretização da imagem urbana não se determina ao largo dos conflitos sociais, em especial àqueles que se constroem a partir da relação entre cultura e política. São, na verdade, o resultado destas disputas. A realização e consolidação do projeto-síntese ligado à intelligentsia urbana não podem se construir alheias às representações populares e aos seus meios políticos e estéticos de negociação. Neste sentido, as políticas culturais tornam-se um espaço essencial para a coalizão que constrói o projeto empreendedor urbano.

Tampouco as dimensões das políticas culturais no plano urbano podem se esquivar de tematizar o nível de intervenção empreendedor na cidade, sob pena de que a multiplicidade de experiências urbanas e a dimensão da alteridade como projeto central do campo político-cultural sejam submetidas ao projeto de reorganização do capital e ao seu modo correspondente de consumo cultural. Um processo concomitante merece ser observado, neste sentido. As cidades pensadas como "caldeirões de criatividade", termo incorporado recentemente no Brasil, têm sido objeto de investimentos atraentes para a diversificação dos discursos acerca da gestão urbana e da gestão cultural. Conjugando o desenvolvimento econômico urbano às formas identificadas de cadeias de produção da cultura, a concepção de criatividade, transportada para o cenário urbano, atua de forma semelhante ao investimento discursivo do marketing urbano - quando não raramente se identifica imediatamente a ele. 


\section{Marketing urbano e a dimensão da criatividade: colonização iminente do capitalismo flexível?}

Tal como o city marketing, estas formas de organização da gestão urbana identificadas com o universo gerencial especializado das indústrias culturais e do turismo, podem internalizar uma "finalidade de classe", orientada aos mesmos usuários solventes - as classes criativas de Florida - a que se dedicam a mercadoria urbana distintiva. Não raro encontrar nas fontes de produção discursiva daqueles que tanto "criam" os "criativos" como as "condições urbanas para a criatividade" (condições que, por vezes, já mostram reais, mas que necessitam de uma certificação especializada para serem percebidas como tais) as mesmas referências que marcam a colonização do empreendedorismo urbano: a critica ao planejamento centralizador do Estado e a denúncia de sua incapacidade; o empoderamento político de uma sociedade civil sem contradições aparentes; a produção identificada aos consultores e sua elevação social como pioneiros; a naturalização da competitividade entre cidades; a apresentação de cases de sucesso, apresentados como uma verdade transponível a condições urbanas muito diferenciadas; e a necessidade de mostrar-se como a saída única para o enfrentamento da crise do período fordista ("be creative or die").

Como projeto, a concepção dos consultores da economia criativa pretende dotar as cidades das forças para as formas futuras de competitividade, combinando um modelo de desenvolvimento espacial com base na capacidade de atrair os trabalhadores criativos e construir assim um efeito cascata de desenvolvimento combinado para todo o território.

Entretanto, esta construção não faz nenhuma distinção imediata entre as cidades de maior ou menor porte, de maior ou menor capacidade de investimento, entre as diferenciações no tratamento imobiliário, ou de como as elites urbanas investem de forma particular. Também é possível notar o silêncio sobre os ciclos de gentrificação resultantes dos processos de regeneração urbana cujo mote central é a cultura.

De certa maneira, a elevação da onda criativa como modelo de gestão parece coexistir com problemas sociais urbanos, sem precisar resolvê-los (PECK, 2010). Para não tornar-se um manual de auto-ajuda para cidades em crise ou um modelo de urbanismo cool, é necessário perguntar-se sobre os limites desta criatividade proposta por seus pensadores. É possível questionar se a presença de trabalhadores criativos é a fonte real de um crescimento econômico ou se, na verdade, ela é resultante de uma ordem de investimentos relacionados ao empreendedorismo urbano, que destaca a necessidade de comercialização de fatores potenciais únicos para cada cidade. Desta forma, as cidades, em todo mundo, parecem se organizar, de uma forma geral, para uma finalidade: se parecer mais cidades europeias e norte-americanas "pós-industriais e bem-sucedidas", que enxergam nas classes criativas - artistas ou brokers - a solução para o problema do desemprego urbano. 
Tal como afirmei, há pouco, sobre a relação entre o city marketing e as políticas culturais, a dimensão da economia criativa também interfere nas políticas culturais, desta vez de forma mais explícita. No caso brasileiro, é possível reconhecer o investimento de órgãos de governo - em todos os seus entes federados - e de empresas consultoras em economia criativa produzindo uma nova cartilha para o tratamento do binômio cultura/desenvolvimento. A capilaridade destas iniciativas parece ainda restrita a poucos atores. Porém, tal como no caso do city marketing, a concepção de criatividade também pode ser disputada. Em especial, uma que se apresente com centralidade popular e extensão suficiente para incorporar as demandas ético-identitárias ao desenvolvimento econômico e sua espacialização derivada.

Para não ser apenas uma coqueluche passageira, é necessário, portanto, determinar em que grau o empreendedorismo urbano e a cidade criativa podem colonizar as políticas culturais e quais as heranças para a dimensão da alteridade que o emprego de uma gestão urbana identificada com a mercado-técnica trará. A dimensão processual da criatividade, aplicada ao cenário urbano, deve, portanto, reconhecer que a estrita relação da flexibilização econômica aos meios de produção e disseminação simbólicos vivem na realidade material contemporânea um espectro de crise. Na mesma medida em que a noção de criatividade permite renovar o repertório de categorias, ampliar a dimensão tipológica e o número de produtores do mercado de bens simbólicos, é também necessário que seu escopo não se centralize apenas no consumo identificado com o modo de vida de uma classe média. Da mesma forma, é necessário que este movimento invista com cuidado à aparente fatalidade de vínculos empregatícios condenados à flexibilização.

Desta maneira, creio serem necessárias algumas questões finais, para pontuar possibilidades de interlocução entre as dimensões criativas propostas às políticas culturais e os meios de ação e gestão sobre o urbano. i) É possível atender ao mercado externo e propiciar uma política que compreenda a multiplicidade de experiências urbanas, inclusive em seu mercado de bens culturais? ii) Como agregar a questão urbana e um mercado de bens com centralidade popular? iii) É possível congregar espaços de produção, festas e feiras (permanentes e transitórios) com a habitação popular para conter assim os processos de gentrificação? iv) Que outras experiências econômicas podem compreender o aspecto estético popular na tematização da criatividade?

\section{Bibliografia}




\section{Marketing urbano e a dimensão da criatividade: colonização iminente do capitalismo flexível?}

ACSELRAD, Henri. Desregulamentação, contradições espaciais e sustentabilidade urbana. Revista Paranaense de Desenvolvimento, n. 107, jul./dez. Curitiba: Ipardes, 2004.

ARIZPE, Lourdes e ALONSO, Guiomar. Cultura, Comercio y Globalización. In: MATO, Daniel (Org.). Cultura, Política y Soeiedad. Perspectivas latinoamericanas. Buenos Aires: CLASCO, 2005.

BOLAÑO, César. Indústria Cultural: informação e capitalismo. São Paulo: Hucitec/Polis, 2000.

BRAGA, J.C. A financeirização da riqueza. In: Revista Economia e Sociedade, Revista do Instituto de Economia da Unicamp. Campinas/SP: Editora da Unicamp, Ago., No 2, 1993.

BREITBACH, Áurea. Novas tecnologias e organização do espaço: considerações preliminares. Ensaios FEE: Porto Alegre, p 693-698, 1992.

CANCLINI, Nestor García. Reconstruir políticas de inclusão na América Latina. In.: UNESCO. Políticas culturais para o desenvolvimento: uma base de dados para a cultura. Brasília: UNESCO Brasil, 2003.

CLARK, T. N.; LLOYD, R.; WONG, K. K.; JAIN, Pushpam. Amenities Drive Urban Growth. Journal of Urban Affairs, vol. 24, no. 5, p.493-515, 2002.

FAISTEIN, Susan. Promoting Economic Development: Urban Planning in the United Sates and Great Brittan. Journal of the American Planning Association, v 57, n1, p2233, 1991.

FEATHERSTONE, Mike. Cultura de consumo e pós modernismo. São Paulo: Studio Nobel, 1995.

FLORIDA, Richard. Cities and the Creative Class. Nova Iorque: Routledge, 2005.

FLORIDA, Richard. The Rise of the Creative Class: And How It's Transforming Work, Leisure, Community and Everyday Life. Nova Iorque: Basic Books, 2002.

HARVEY, David. A produção capitalista do Espaço. São Paulo: Annablume, 2006.

JAMESON, Fredric Pós-modernismo. A lógica cultural do capitalismo tardio. São Paulo: Ática, 1996.

KLEIN, Naomi. Sem logo. A tirania das marcas em um planeta vendido. Rio de Janeiro: Record, 2002.

KRATKE, Stefan. The new urban growth ideology of "creative cities". In: Brenner, Neil; Marcuse, Peter; e Mayer, Margit. Cities for people, not for profit: an introduction. Londres, Nova Iorque: Routledge, 2012.

LANDRY, Charles e BIANCHINI, Franco. The creative city. Londres: Demos, 1995. MIGUEZ, Paulo. Economia criativa: uma discussão preliminar. In: NUSSBAUMER, Gisele Marchiori (Org.). Teorias e politicas da cultura: visões multidisciplinares. Salvador: EDUFBA, 2007.

PECK, Jamie. Constructions of neoliberal reason. Oxford University Press, Oxford, 2010. 
POSSAS, Mario. Em direção a um paradigma microdinâmico: a abordagem neoschumpeteriana. In: Ensaios sobre a Economia Política Moderna - teoria e história do pensamento econômico. São Paulo: Editora Marco Zero, 1989.

REIS, Ana Carla Fonseca, et al. Economia criativa : um conjunto de visões. São Paulo : Fundação Telefônica, 2012.

RUBIM, Albino. Dos Sentidos do Marketing Cultural. In: Revista Textos. Salvador: Departamento e Programa de Pós-graduação FACOM/UFBA, 1998.

SÁNCHEZ, Fernanda. Cidade Espetáculo: Política, Planejamento e City Marketing. Curitiba: Palavra, 1997.

SÁNCHEZ, Fernanda. A reinvenção das cidades para um mercado mundial. Chapecó: Argos, 2010.

SCHNEIDER, S . Território, Ruralidade e Desenvolvimento. In: VELÁSQUEZ LOZANO, Fabio.; MEDINA, Juan Guillermo Ferro (Editores). (Org.). Las Configuraciones de los Territorios Rurales en el Siglo XXI. 1 ed. Bogotá/Colombia: Editorial Pontifícia Universidad Javeriana, 2009, v. 1, p. 67-108.

TASCHNER, Gisela. A pós-modernidade e a sociologia. In: Revista USP, no 42 , jun-julago 1999.

VAINER, Carlos. Os liberais também fazem planejamento urbano? In: ARANTES, Otília; VAINER, Carlos; MARICATO, Ermínia. A cidade do pensamento único: desmanchando consensos. Petrópolis: Vozes,

ZUKIN, Sharon. The Cultures of Cities. Oxford: Blackwell, 2006. 